\title{
Studies of Novel Heterocyclic Insensitive High Explosive Compounds: Pyridines, Pyrimidines, Pyrazines and Their Bicyclic Analogues
}

\author{
Ross W. Millar*, Simon P. Philbin, Robert P. Claridge and Javid Hamid
}

Future Systems Technology Division, QinetiQ Ltd., Building X59, Fort Halstead, Sevenoaks, Kent TN14 7BP, (United Kingdom)

\begin{abstract}
The rationale behind using heterocyclic compounds [1], particularly nitrogen heterocycles, as higher energy insensitive high explosives is discussed, including the potential advantages compared with carbocyclic compounds. The types of functional groups used to impart energy to heterocyclic nuclei, whilst maintaining insensitivity, and methodologies for their introduction, are covered. The latter include nitration (by conventional and clean synthetic methods), amination, and oxidation (on ring heteroatoms and of exocyclic amino groups). Strategies for maximising the energetic content of a given heterocyclic nucleus are also examined. The syntheses of specific examples at QinetiQ are described, based on the following nuclei: pyridine, pyrimidine, pyrazine, quinoxaline, quinazoline, pteridine and purine. Strategies for obtaining the desired amino-nitro derivatives and their heterocyclic $\mathrm{N}$-oxides are outlined. Optimisation of the synthetic routes for several candidates is discussed. The physical, explosive and thermal properties of the more successful candidates are described, with suggestions for their potential application in military stores.
\end{abstract}

Keywords: Insensitive Explosive, Heterocycle, Nitration, Amination, N-Oxidation.

\section{Background}

High performance has been for many years the driving force behind research in the field of explosive compounds for use in military warheads. Thus TNT, used up to and including World War I, was replaced by more powerful RDX-TNT mixtures between the two wars and in World War II. In turn, once HMX became available commercially (ca. 1960) it replaced RDX in the highest performance compositions, which contain high proportions of this ingredient in either melt-cast (octols) or polymer bound (e.g. LX-14) compositions.

Although research to find explosive molecules with higher performance than HMX continues, many initially promising candidates have fallen by the wayside for various reasons [2], for instance tetranitroglycoluril, hexanitrobenzene and, recently, trinitroazetidine (TNAZ). Others, e.g. CL-20 and polynitrocubanes, are still under consideration, but seem unlikely in the short term to replace HMX as a high

* Corresponding author; e-mail: rwmillar@QinetiQ.com tonnage ingredient; the significance of this conclusion will be amplified below.

Since the 1970s the problem of warhead vulnerability has become increasingly more acute. To enhance resistance to aggressive stimuli (e.g. fire, bullet or fragment impact), in early work composite explosives were developed consisting of a three-dimensional polymer matrix encasing a conventional granular explosive (HMX etc.).

However, increased intensity of attack on the warhead means that these conventional compositions fail to provide the required immunity to stimuli and alternative remedies must be sought. The approaches are twofold:

(i) To incorporate a higher proportion of the polymer in the composition, thereby improving the isolation of the explosive particles and reducing their susceptibility to the stimuli, or

(ii) To use explosives which are intrinsically less sensitive; thus the proportion of polymeric binder can be maintained at a similar (low) level to traditional compositions.

Each approach is currently under investigation and their respective advantages and disadvantages are now briefly analysed.

The first approach has the major drawback that, other things being equal, the performance of the composition is reduced. To restore it to the previous level requires either: a) use of a higher energy explosive filler, or b) incorporation of energy in the binder molecules. As we have seen above, option a) is currently in abeyance owing to the nonavailability of suitable higher performance explosives (at least on tonnage scale - with the possible exception of CL-20, although problems remain with the production of this compound and its qualification). Approach b) is currently being pursued with the use of energetic polymeric binders such as PolyNIMMO, PolyGlyN and BAMO copolymers; discussion of the results of these studies falls outside the scope of the present paper, but it should be borne in mind that, if compositions can be produced which satisfy the requirements for service use (particularly thermal stability and ageing tests), then a solution to the problem will have been found. 


\section{Research Approach}

Turning to the approach ii) above, the use of intrinsically less sensitive explosives, historically this approach has been hampered by the lack of suitable candidate molecules possessing adequate performance. Few thermally-stable explosive molecules with low impact sensitivity were known before the 1960s [3, 4]; the only compound reaching any appreciable production level in this era was TATB and although it has been incorporated in many compositions its performance is highly inferior to that of HMX and is often deemed inadequate. Its suitability is also compromised by problems in its synthesis, notably in getting rid of chloride contaminants and also achieving suitable particle size distributions for formulating. The shortcomings in its explosive performance are seen as low power output (i.e. low detonation pressure), large critical diameter when unconfined plus the likelihood of incomplete detonation unless large booster charges are used. TATB, in the authors' opinion, continues to be used only because no better alternative has been found.

Research during the space race in the 1960s and 70s turned up a number of thermally stable explosives, many with improved performance over TATB, notably HNS and PYX (and other related heterocyclic compounds), but none exhibited sufficient all-round improvement in properties to replace TATB. Latterly, efforts have concentrated on "novel" heterocycles such as NTO (actually first synthesised in 1906, but virtually ignored for some 60 years thereafter), and although results for compositions containing this compound (either as sole energetic ingredient or, more often, in admixture with RDX) have been promising [5, 6], there still remain problems arising from the compound's large critical diameter when unconfined, which may give rise to incomplete detonation, as well as some undesired effects arising from its acidic nature $\left(\mathrm{pK}_{\mathrm{a}}=3.67\right.$ [6]). Therefore, it remains a desirable aim to develop a compound or compounds which possess low sensitiveness whilst maintaining high explosive performance. Novel approaches to achieve this aim are now considered in more detail.

\section{IHE Compounds}

The principal approach to new types of insensitive HEs described here is based on the incorporation of a higher proportion of nitrogen into the explosive molecules. This approach requires the following chemistries: a) use of nitrogen-rich heterocycles as a nitratable nucleus, with polyamino substitution to reduce sensitiveness, or b) the incorporation of heterocyclic $\mathrm{N}$-oxide functions in conjunction with polyamino substitution; in certain target molecules both approaches are combined. These approaches are applied to three classes of compounds: i) monocyclic heterocycles, ii) bicyclic heterocycles with one heterocyclic ring, and iii) bicyclic heterocycles with two heterocyclic rings, and each class is considered separately.
The aim is to obtain amino- or aminonitroheterocycles which can either be used as insensitive HEs in their own right (particularly aminonitroheterocycles), or used as precursors for $\mathrm{N}$-oxidation, which will impart higher energy to the molecule. In certain cases appropriate aminoheterocycles, for instance the precursor for DADNPO (see below), or rarely aminonitroheterocycles, were commercially available. In general, though, this was not the case and the approach was to select commercially available halo- or halonitroheterocycles, either chloro or fluoro derivatives. (Fluoro derivatives are preferable since the rate of halide displacement is enhanced.) The appropriate halo- or halonitroheterocycle was then aminated and the resulting amino- or aminonitroheterocycle was $\mathrm{N}$-oxidised, where possible.

\subsection{Monocyclic Heterocycles}

\subsubsection{General}

Attention was focussed mainly on pyrazine and pyrimidine derivatives, since other monocyclic heterocyclic nuclei (e.g. pyridazines, triazines) had proven less amenable to study. Some work on pyridine derivatives is mentioned later.Thus a pyrazine derivative, ANPZ-i 1, was studied, which is an isomer of ANPZ 2 [7,8], which is the precursor for the N-oxide $\mathbf{3}$ developed at Lawrence Livermore National Laboratory and known as PZO or LLM-105 [7]. $\mathrm{PZO}$ is under evaluation as an insensitive $\mathrm{HE}$ filler compound, although its synthesis requires an expensive precursor compound, 2,6-dichloropyrazine which detracts from its usefulness.

The synthesis of ANPZ-i 1 was fully described elsewhere $[9,10]$, and it is a useful explosive in its own right $\left(\mathrm{P}_{\mathrm{CJ}}=34.9\right.$ $\mathrm{GPa}[10])$; it is also obtainable from a cheaper precursor (glycine anhydride) than PZO. However it should be noted that conditions to effect the full oxidation of ANPZ-i, which would give the novel explosive PZDO 4, have not been found. The detonation pressure $\left(\mathrm{P}_{\mathrm{CJ}}\right)$ of $\mathrm{PZDO}$ was calculated to be $40.2 \mathrm{GPa}$ [10].

Further developments in the pyrimidine work are now presented. Nitration and $\mathrm{N}$-oxidation of two aminopyrimi-

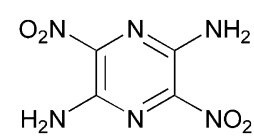

1<smiles></smiles><smiles>Nc1nc(N)c([N+](=O)[O-])nc1[N+](=O)[O-]</smiles>

2

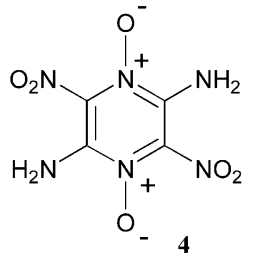




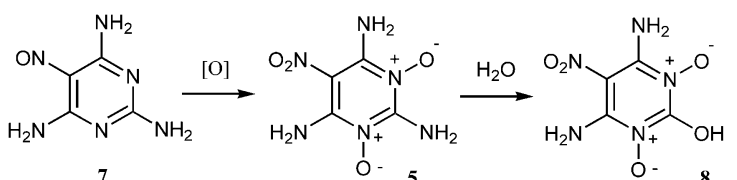

Scheme 1. Preparation of 5-nitro-2,4,6-triaminopyrimidine-1,3dioxide $\mathbf{5}$.

dines were intensively studied, with a view to synthesising target novel insensitive HE molecules: these were 5-nitro2,4,6-triamino-pyrimidine-1,3-dioxide 5) and 5-nitro-4,6diaminopyrimidine-1,3-dioxide 6). In the case of the latter compound it was found expedient to synthesise the precursor amino compound from the chloro precursor (see below). Compounds 5 and $\mathbf{6}$ are now discussed in turn.

\subsubsection{5-Nitro-2,4,6-Triaminopyrimidine-1,3-Dioxide (5)}

Although 5 was reported in the 1960s [11], it was not evaluated as an insensitive $\mathrm{HE}$ in this work. In a later publication [12] the preparation and preliminary evaluation of 5 as an insensitive HE were reported but no conclusions were reached about its suitability for this use, and doubts were cast over its stability, particularly towards hydrolysis. In the present work it is demonstrated that $\mathbf{5}$ is a suitable candidate for insensitive $\mathrm{HE}$ applications and it is also adequately stable for this purpose.

5 was prepared in 51\% yield by the reaction of 5-nitroso2,4,6-triaminopyrimidine 7 with $30 \%$ hydrogen peroxide in trifluoroacetic acid, using a procedure much modified from that reported in the literature [11], Scheme 1. The major problems encountered in this synthesis were: i) preventing the isolation of incompletely oxidised product (i.e. 5-nitro2,4,6-triaminopyrimidine-1-oxide), and ii) avoiding decomposition of the product by hydrolysis (to give 8). The former problem was overcome by judicious choice of solvents and conditions to inhibit the premature precipitation of the monoxide, whilst the purification described in the literature had to be amended to prevent inadvertent conversion of 5 to 8. Batches of 5 of some $16-17 \mathrm{~g}$ were then prepared routinely and submitted for hazard testing.

5 has a density (from pycnometric studies) of $1.81 \mathrm{gcm}^{-3}$, giving a calculated detonation pressure of $28.8 \mathrm{GPa}$ [13]. The hazard properties of this compound have now been assessed (see Fig. 1). The figure of insensitiveness (F of I) of 91 $(\mathrm{RDX}=80)$, although less than certain IHEs - e.g. for NTO, F of $I=100$ [14] - nevertheless qualifies 5 as an insensitive material and its behaviour in the friction tests places it in this category also. The electrostatic and train tests suggest likewise that no problems will be encountered in the handling of 5. Finally, the temperature of ignition (T of I) figure of $256^{\circ} \mathrm{C}$ is again somewhat intermediate in behaviour - e.g. for RDX, T of $\mathrm{I}=219^{\circ} \mathrm{C}$ [15], but for NTO, T of $\mathrm{I}=259^{\circ} \mathrm{C}[14]$. Therefore these data indicate that hazards in handling $\mathbf{5}$ are well within accepted limits and there should be no problems in scaling up its production. Once larger<smiles>Nc1c([N+](=O)[O-])nc([N+](=O)[O-])c(N)[n+]1[O-]</smiles>

PZO (3)

$\mathrm{C}_{4} \mathrm{H}_{4} \mathrm{~N}_{6} \mathrm{O}_{5} ; \mathrm{P}_{\mathrm{C}-\mathrm{J}} 33 \mathrm{GPa}$

$\mathrm{F}$ of $\mathrm{I}=54(\mathrm{RDX}=80)$ $F$ of $F=5.2$ (insens.) Mallet: Steel/steel Train: Supports Electrostat: : $4.5 \mathrm{~J}($ not $0.45 \mathrm{~J})$<smiles>Nc1[nH+]c(N)[n+]([O-])c(N)c1[N+](=O)[O-]</smiles>
O.

NTAPDO (5)

$\mathrm{C}_{4} \mathrm{H}_{6} \mathrm{~N}_{6} \mathrm{O}_{4} ; \mathrm{P}_{\mathrm{C}-\mathrm{J}} 28,8 \mathrm{GPa}$

$\mathrm{F}$ of $\mathrm{I}=91(\mathrm{RDX}=80)$

of $F=5.5$ (insens.)

$\mathrm{T}$ of $\mathrm{I}=256^{\circ} \mathrm{C}$

T of $\mathrm{I}=256^{\circ} \mathrm{C}$
Train: Supports

Electrostat:: $4.5 \mathrm{~J}($ not $0.45 \mathrm{~J})$
Figure 1. Properties of novel insensitive explosives (pyrazines/ pyrimidines).

amounts of the material are to hand, it will be possible to initiate a programme of functional testing to evaluate the performance of $\mathbf{5}$ as a component of an explosive train, and together with large-scale hazard test results, assess its suitability as a component of insensitive munitions.

Work on the thermal stability of 5 (5-nitro-2,4,6-triaminopyrimidine-1,3-dioxide) has been carried out. For comparison, data were also obtained for another heterocyclic $\mathrm{N}$-oxide explosive, PZO $\mathbf{3}$, as well as a non-N-oxide containing heterocyclic explosive, ANPZ 2.

When heat flow calorimetry (HFC) measurements were made on the explosives mentioned above, together with TATB as a reference compound, very low heat flows were obtained from all four compounds, with ANPZ and TATB apparently giving the lowest values. Although the data were insufficiently consistent to permit calculations to be made of the activation energies of the respective compounds towards decomposition, a plot of $\ln$ (rate constant) vs. 1/T (in Kelvin) gave the Arrhenius plot shown in Fig. 2. There was a marked non-linear relationship between $\ln (\mathrm{P})$ and $1 / \mathrm{T}$ at the high and low temperatures. This variation was thought, in the case of $\mathbf{5}$ at least, to result from changes in the reaction mechanism of the decomposition at different temperatures.

Nevertheless, it appears from these results that both the $\mathrm{N}$-oxide explosives, $\mathrm{PZO}$ and $\mathbf{5}$, and probably more so $\mathrm{PZO}$, possess sufficient thermal stability to permit their further study as components of formulations, and subject to satisfactory chemical compatibility with other likely components of such formulations (i.e. binders, plasticisers, stabilisers etc.), they should be considered for such testing.

\subsubsection{5-Nitro-4,6-Diaminopyrimidine-1,3-Dioxide (6)}

As the labile 2-amino substituent of 5-nitro-2,4,6-triaminopyrimidine $\mathbf{5}$ had been identified as a potentially destabilising component of that pyrimidine, it was decided to investigate the synthesis of an analogue without such a group, namely 5-nitro-4,6-diaminopyrimidine-1,3-dioxide $\mathbf{6}$. Rather than start by nitrating the corresponding diamino compound (9, Scheme 2) to give 5-nitro-4,6-diaminopyrimidine 10, it was felt that using the dichloro precursor $\mathbf{1 1}$ would be an attractive option since this is a readily available 
Variation of In P with 1/T for NTAPDO

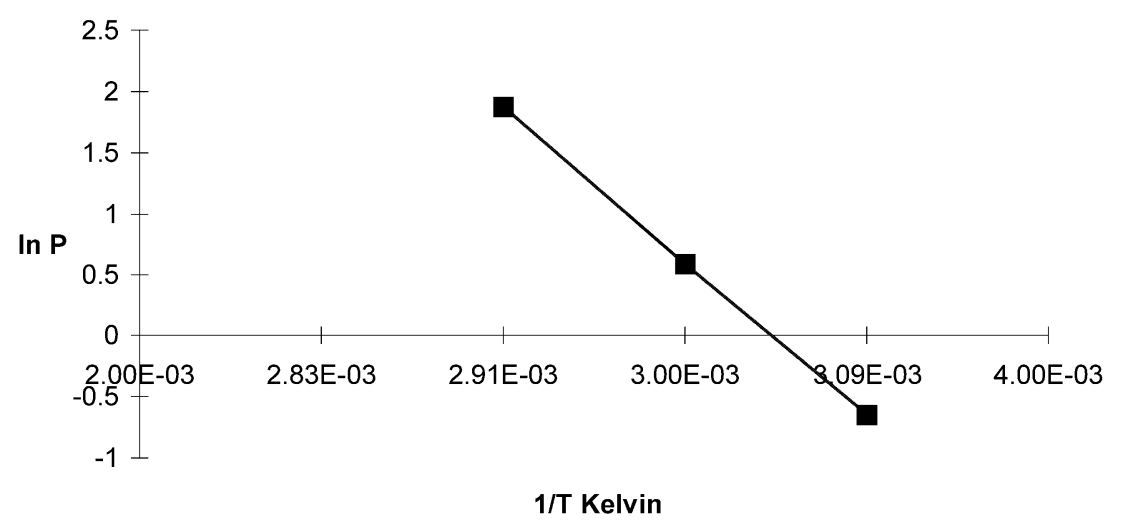

Figure 2. Arrhenius plot for NTAPDO 5.

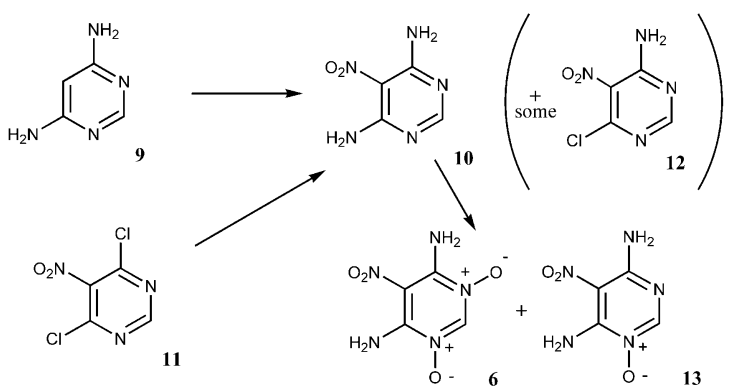

Scheme 2. Preparation of 5-nitro-4,6-diaminopyrimidine-1,3-dioxide 6.

compound. However, previous studies [16] had shown that the diamination of $\mathbf{1 1}$ is more difficult than expected, and under normal conditions only the mono-amino derivative $\mathbf{1 2}$ together with some $\mathbf{1 0}$ may be isolated (Scheme 2).

Further literature research revealed that aminations may be carried out under more forcing conditions using direct injection of ammonia gas into a solution of the substrate in phenol at $140^{\circ} \mathrm{C}$ [17]. When these conditions were employed in the amination of $\mathbf{1 1}$, a great improvement in the amination was observed, and after $4 \mathrm{hr}$ under these conditions the diamino product was isolated in around $90 \%$ yield.

The oxidation of $\mathbf{1 0}$ has still proved problematical, with mixtures of mono- and di-N-oxides (13 and $\mathbf{6}$ resp.) being obtained under a wide variety of conditions. Presumably the ring nitrogen atoms in this compound, being flanked by only one amino substituent instead of two as in the triamino compound, are less labile to N-oxidation, an effect well known with this class of compound [18]. Further development work is therefore required in this reaction before sufficient $\mathbf{6}$ becomes available for hazard testing. It should be remembered that $\mathbf{6}$, although possessing a slightly lower predicted detonation pressure than $\mathbf{5}(27.8 \mathrm{vs}$. $28.8 \mathrm{GPa})$, is nevertheless expected to show enhanced chemical stability due to the absence of a labile amino substituent at the 2position; the optimisation of its synthesis therefore remains a worthwhile aim.

\subsubsection{Aminonitropyridines}

The compound DADNPO 14, originally reported in 1993 [19] and investigated subsequently in the US [20], was also synthesised at QinetiQ in the late 1990s [21] and found to have high insensitiveness, although somewhat low explosive power $-\mathrm{P}_{\mathrm{CJ}}($ calc. $)=27.7 \mathrm{GPa}$.

Therefore, efforts in the area of pyridine derivatives were focussed on the target trinitro compound $\mathbf{1 5}$, which would have higher explosive power and is a more challenging synthetic target. In this instance the problem of effecting pentasubstitution of the pyridine ring meant that a preferred approach was to use fluorinated precursors, which are known to be more readily displaced by nitrogen nucleophiles such as ammonia [22]. In fact, the synthesis route was based on a specially synthesised fluoropyridine, 3,5-difluoropyridine [23], but studies failed to yield the desired product, and instead, in work reported elsewhere [23, 24], the intermediate $\mathbf{1 6}$ was the only isolable product.<smiles>Nc1c([N+](=O)[O-])cc([N+](=O)[O-])c(N)[n+]1[O-]</smiles>

14<smiles>Nc1c([N+](=O)[O-])nc([N+](=O)[O-])c(N)c1[N+](=O)[O-]</smiles>

15<smiles>Nc1c[n+]([O-])cc(N)c1[N+](=O)[O-]</smiles>

16 
Finally, methods were investigated in order to convert exocyclic amino groups on heterocyclic nuclei into nitro groups, i.e.

Het $-\mathrm{NH}_{2} \rightarrow$ Het- $\mathrm{NO}_{2}$

where Het $=$ e.g. pyridine $(2-/ 4-)$

However, with the two oxidising systems tried, peroxytrifluoroacetic acid in dichloromethane or dimethyldioxirane (DMD) in acetone, yields of less than $5 \%$ of the desired nitro compounds were obtained, together with small amounts of products resulting from further oxidation ( $\mathrm{N}$-oxides, e.g. 2-nitropyridine-N-oxide). These routes were therefore not pursued further for the synthesis of nitroheterocycles.

\subsection{Bicyclic Heterocycles}

\subsubsection{Benzodiazines - Quinoxalines and Quinazolines}

In a similar manner to the monocyclic heterocycles particularly pyrazines and pyrimidines - mentioned above, it was anticipated that bicyclic heterocycles with one fused benzene ring - quinoxalines 17 and quinazolines 18 could be functionalised with nitro, amino and $\mathrm{N}$-oxide groups to give insensitive HEs such as $\mathbf{1 9}$ or 20. Calculations have shown that these derivatives would be moderately powerful explosives - e.g. 19: $27.1 \mathrm{GPa}, 20: 28.6 \mathrm{GPa}$ - and they should be thermally stable. Further details of this strategy are discussed elsewhere [9].

The functionalisation of these types of heterocycles turned out to be more difficult than expected. Initially the nitration of chloroquinoxalines was investigated, with the aim of aminating the nitro derivatives to give compounds which would be precursors for $\mathrm{N}$-oxide target compounds such as 19. However, only one chloroquinoxaline was successfully nitrated - 2,3,6-trichloroquinoxaline 21, which gave the 5-nitro derivative 22, a new compound, in $64 \%$ yield. Other chloroquinoxalines withdifferent degrees of

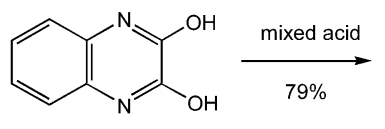

24

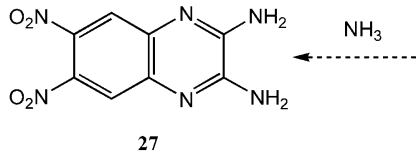

27<smiles>O=[N+]([O-])c1cc2nc(O)c(O)nc2cc1[N+](=O)[O-]</smiles>

25 1. $\mathrm{NaH}$<smiles>COc1nc2cc([N+](=O)[O-])c([N+](=O)[O-])cc2nc1OC</smiles>

26
Scheme 3. Proposed preparation of 2,3-diamino-6,7-dinitroquinoxaline 27.

chloro substitution, e.g. 2,3-dichloro- or 2,3,6,7-tetrachloroquinoxalines, either failed to react or decomposed under a wide range of reaction conditions. Surprisingly, little success was achieved in nitrating aminoquinoxalines (e.g. 2,3-diaminoquinoxaline, 23) either, and decomposition generally supervened in this type of reaction. Therefore the strategy was changed and hydroxy- or alkoxyquinoxalines were used instead as substrates, and some nitrated products were obtained (Scheme 3): thus 2,3-dihydroxyquinoxaline $\mathbf{2 4}$ was nitrated readily to the dinitro compound $\mathbf{2 5}$ [25], which formed the dimethoxy derivative 26, a compound not hitherto reported and which should be readily converted to the diamine 27.

However, this compound proved resistant to amination using conventional reagents (ethanolic or liquid ammonia under pressure), although there are indications from the literature [26] that such transformations may be achieved vicariously using nucleophilic aminating agents. Although time did not permit this strategy to be employed with quinoxalines, a successful amination of this type is reported for quinazolines (see below). Thus, although some new compounds were synthesised as intermediates, none of the quinoxaline target molecules (of the type 19) could be synthesised in this work.<smiles>c1ccc2nccnc2c1</smiles>

17<smiles>c1ccc2ncncc2c1</smiles><smiles>Nc1c([N+](=O)[O-])c(N)[n+]([O-])c2nc([N+](=O)[O-])c([N+](=O)[O-])c([N+](=O)[O-])c12</smiles>

19<smiles></smiles>

20<smiles>Clc1ccc2nc(Cl)c(Cl)nc2c1</smiles>

21<smiles>Cc1nc2ccc(Cl)c([N+](=O)[O-])c2nc1C</smiles><smiles>Nc1nc2ccccc2nc1N</smiles> 
Quinazolines are likewise in general resistant to nitration, with ring breakdown generally supervening, for instance in the attempted nitration of 2,4-dichloroquinazoline $\mathbf{2 8}$. However, ring synthesis with the nitro groups already in place is a viable strategy with this ring system, and the dinitrodiamino compound $\mathbf{2 9}$, readily prepared from simple starting materials [27], was used as a key intermediate.<smiles>Clc1nc(Cl)c2ccccc2n1</smiles><smiles>Nc1nc(N)c2cc([N+](=O)[O-])cc([N+](=O)[O-])c2n1</smiles>

29 could be further functionalised to 30, a hitherto unreported compound, by vicarious amination using trimethylhydrazinium iodide [28] (Scheme 4). 30 is a useful intermediate en route to targets such as $\mathbf{2 0}$, but time did not permit further elaboration of this molecule. Nevertheless, $\mathrm{N}$-oxidation to give the related molecule $\mathbf{3 1}$ was successfully achieved, starting from $\mathbf{2 9}$ and using 60\% hydrogen peroxide in trifluoroacetic acid, indicating that $\mathrm{N}$-oxidation of such systems is feasible (Scheme 4). The product, $\mathbf{3 1}$, is a hitherto unreported compound. Reduction of $\mathbf{2 9}$ gave the tetraammine 32 [29] but unfortunately this compound decomposed upon attempted nitration.

Therefore, it did not prove possible to synthesise any of the target insensitive $\mathrm{HE}$ molecules in the quinazoline series.

\subsubsection{Heterocycles with Both Rings Heterocyclic-Pteridines and Purines}

Work in this area was directed towards target molecules in which both rings are heterocyclic (cf. benzoheterocycles, above). Although the synthetic routes are somewhat more complex, the potential pay-off is greater since a higher proportion of nitrogen can be incorporated in the heterocyclic nuclei. The family of compounds selected for initial studies was the pteridines $\mathbf{3 3}$, in which a pyrimidine nucleus is fused to a pyrazine ring, giving a nitrogen-rich system ( $\mathrm{N}: \mathrm{C}$ ratio 4:6); further studies (see below) included the purine system 34 in which an even higher ratio is achieved (4:5) [ring numbering conventions are shown for each ring system].<smiles></smiles><smiles>c1ncc2nc[nH]c2n1</smiles>

Two possible target pteridine molecules which may be attainable using the synthetic strategy discussed below are shown (35 and 36):<smiles>Nc1nc([N+](=O)[O-])c2c(n1)[n+]([O-])cc([N+](=O)[O-])[n+]2[O-]</smiles><smiles></smiles>

The strategy consisted of synthesising appropriately substituted monocyclic precursors, e.g. 2-amino-3-cyano6-(oximinomethyl)pyrazine-1-oxide 37, onto which could be built a second ring through a condensation reaction with a simple substrate (e.g. guanidine; see Scheme 5) to give the pteridine 38 [30]. The key intermediate, 37, arose from the acyclic precursors dioximinoacetone 39 [31] and a malononitrile derivative $\mathbf{4 0}$ :<smiles>Nc1cc(N)c2nc(N)nc(N)c2c1</smiles>

Scheme 4. Reactions of 2,4-diamino-6,8-dinitroquinazoline 29. 


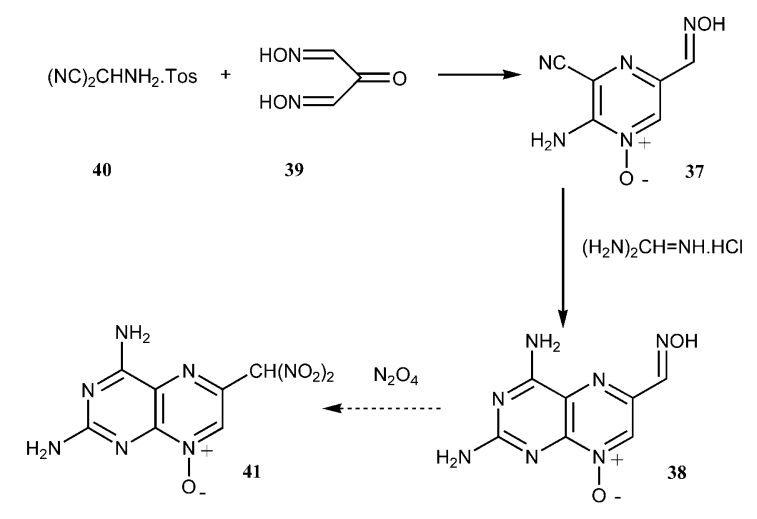

Scheme 5. Synthesis of a pteridine derivative $\mathbf{3 8 .}$

The penultimate stage in the synthesis (before further $\mathrm{N}$-oxide functionalisation to give $\mathbf{3 5}$ or $\mathbf{3 6}$ ) is to convert the oxime function to a gem-dinitro function by the Ponzio reaction [32], giving the intermediate 41. However, problems were encountered in the scale-up of $\mathbf{3 8}$ on account of its total insolubility, and hence subsequent attempted transformations such as $\mathrm{N}$-oxidation or conversion of the amino group(s) on the pyrimidine ring to give energetic products such as those mentioned above $\mathbf{3 5}, \mathbf{3 6}$ were unsuccessful.

Because of the insolubility of the pteridines, attention was switched to the purine system, a 6-5 fused ring system containing 4 nitrogen atoms $\mathbf{3 4}$.<smiles>Clc1nc(Cl)c2nc(Cl)[nH]c2n1</smiles><smiles>O=C1NC(=O)C2NC(=O)NC2N1</smiles>

The strategies employed in the synthesis of purine derivatives were as follows: the primary target molecule was the 2,6,8-trichloro derivative $\mathbf{4 2}$, prepared by chlorination of uric acid 43 , a cheap starting material, using phosphorus oxychloride. Problems were encountered in the synthesis of $\mathbf{4 2}$ arising from side-reactions, detailed below. Once these were overcome, the intended monoamination of $\mathbf{4 2}$ in the 6-position, followed by sequential replacement of the chlorine substituents by nitro groups using 'Umpolung' nitration methodology [33], would yield an aminodinitro derivative 44 . This compound could then be further elaborated to an $\mathbf{N}$-oxide derivative such as $\mathbf{4 5}$.<smiles></smiles><smiles></smiles>

The amination of trichloropurine $\mathbf{4 2}$, however, posed some problems, and using a method employing ammoniacal phenol, which had worked successfully in the monocyclic series, a clean product could not be obtained with the purine system owing to attack by phenoxy anion. By changing conditions to ammonia/acetonitrile under pressure (autoclave), the desired product, 6-amino-2,8-dichloropurine $\mathbf{4 6}$ was obtained in an optimised yield of $45 \%$. Unfortunately, once these synthetic precursor problems had been overcome, insufficient time remained to attempt the next step, 'Umpolung' nitration of 46.<smiles>Nc1nc(Cl)nc2[nH]c(Cl)nc12</smiles>

\section{Conclusions}

Several heterocyclic compounds bearing nitro, amino and $\mathrm{N}$-oxide substituents have been studied as potential higher energy replacements for existing insensitive explosives such as TATB and NTO. Two front-runners are shown in Figure 1 - the pyrimidine derivative NTAPDO 5, developed at QinetiQ, and PZO 3, developed at LLNL Calif. [7] - and these are currently the most promising candidates.

A new compound PZDO 4 [9,10], anticipated to have superior power output to either of the above compounds, would, if synthesizable, prove to be the candidate of choice.

An evaluation of the monocyclic system most suitable for scale-up will need to be made, based on its suitability for end-use (i.e. performance, stability, compatibility etc.) and also the economics of production, taking into account cost of starting materials and complexity of the synthetic transformations required. Of the three front-runners, $\mathrm{PZO}$ looks attractive on account of its high predicted $\mathrm{P}_{\mathrm{C}-\mathrm{J}}(33.0 \mathrm{GPa})$ but requires a relatively expensive starting material (2,6-dichloropyrazine). PZDO, on the other hand, originates from a cheap precursor (glycine anhydride) but requires currently expensive reagents to effect the synthetic transformations. NTAPDO 5, although offering lower performance $\left(\mathrm{P}_{\mathrm{C}-\mathrm{J}}=28.8 \mathrm{GPa}\right)$, originates from cheap starting materials and requires fewer synthetic steps, and this advantage may prove decisive and lead to its selection. Although a detailed analysis of costs should be deferred until this selection is made, it is clear that all of these compounds will be much more expensive to produce than current materials such as TATB and NTO.

The syntheses of several benzoheterocycles (quinoxalines and quinazolines) have been investigated but, with a few exceptions, their chemistry is not conducive to the introduction of the types of functional groups mentioned above. In particular, nitrations are difficult to achieve, with decomposition often supervening, and aminations require more carefully chosen conditions than the monocyclic systems (i.e. pyrimidines and pyrazines). A diaminodinitroquinazoline 29 was found to be the most promising intermediate. Therefore, there appears to be little benefit, 
at least for the time being, in investigating the benzodiazines further.

Bicyclic heterocycles with four nitrogen atoms (pteridines and purines) suffered from some of the problems mentioned above but also were generally much less soluble once the functional groups had been introduced, leading to severe handling problems. None of the target molecules could therefore be synthesised. Therefore there appears to be little benefit in investigating further the heterocycles with four nitrogen atoms.

\section{Experimental}

Note: Many of the compounds described here are explosives and appropriate precautions should be taken.

All materials were used as received unless otherwise stated. Chemicals were supplied as follows: organic/inorganic chemicals and solvents by Aldrich Chemical Co. Ltd., Merck (UK) Ltd and Fluka (UK) Ltd.

IR spectra were recorded on a Nicolet 760 Magna series spectrometer, either between $\mathrm{KBr}$ disks (liquids) or as Nujol mulls (solids). ${ }^{1} \mathrm{H}$ NMR measurements were obtained on a Bruker 400 Avance spectrometer operating at $400 \mathrm{MHz}$ using a $5 \mathrm{~mm}$ QMP probe. ${ }^{13} \mathrm{C}$ NMR measurements were carried out on the same instrument at $75 \mathrm{MHz}$. Low resolution mass spectra were obtained on a VG 7070EQ instrument using either chemical ionisation (CI) or electron impact (EI) modes between masses 10 and 400 at 1 decade $\mathrm{s}^{-1}$; high resolution mass spectra were obtained on a VG Analytical ZAB-SE spectrometer in FAB (fast atom bombardment) mode.

HPLC analyses were performed on an ATI Unicam Diamond 600 system with UV detection and using $220 \mathrm{~mm} \times 5 \mathrm{~mm}$ internal diameter columns (packings as shown below). Melting points were determined using a Koefler hotbench, model Leica VM HB. Elemental analyses were carried out in-house on a Perkin-Elmer CHN-2400 instrument with optimisation of mix time and combustion temperature. Results quoted are the average of four analyses.

Autoclave reactions were carried out in a Parr autoclave fitted with a $500 \mathrm{ml}$ bomb. Hydrogenations were performed using a Parr shaker-type hydrogenator (500 ml bottle).

Heat flow measurements were obtained using a Thermometrics thermal activity monitor (TAM) model 2277 fitted with four ampoule measuring cylinders. Samples were tested simultaneously in sealed glass ampoules with Teflon-faced butyl rubber septa. Prior to sealing, the vials were purged with nitrogen gas in order to suppress interference from oxidation reactions.

\subsection{Synthesis of 5-Nitro-2,4,6-Triaminopyrimidine- 1,3-Dioxide 5}

The method of Delia et al. [11] was modified. A solution of 5-nitroso-2,4,6-triaminopyrimidine $7(25.0 \mathrm{~g}, 0.16 \mathrm{~mol})$ in trifluoroacetic acid $(50 \mathrm{ml})$ was added dropwise to a stirred solution of $30 \%$ hydrogen peroxide $(60 \mathrm{ml}, 0.53 \mathrm{~mol})$ in trifluoroacetic acid $(50 \mathrm{ml})$, keeping the temperature below $30^{\circ} \mathrm{C}$. After the addition was complete, the solution was stirred at ambient temperature for $4 \mathrm{~h}$, after which time diethyl ether $(150 \mathrm{ml})$ was added. A precipitate formed which was collected and washed with further diethyl ether and boiling propan-2-ol. The orange solid $\mathbf{5}$ was dried under vacuum, yield $16.7 \mathrm{~g}(51 \%)$, m.pt. $284^{\circ} \mathrm{C}$ (dec.), lit.[12] m.pt. $>264^{\circ} \mathrm{C}$ (dec.). The material gave a positive ferric chloride test indicating $\mathrm{N}$-oxide was present.

The use of other oxidising agents (e.g. perphthalic acid or peracetic acid) or variations of the method given above (e.g. change in mode of addition, shortening or lengthening of reaction time, omission of ether precipitating agent etc.) gave rise to the isolation of products with either a higher mono-N-oxide content, or lower yields, or both.

\subsection{Synthesis of 5-Nitro-4,6-Diaminopyrimidine- 1,3-Dioxide 6}

The method of Albert et al. [17] was used for the preparation of 4,6-diamino-5-nitropyrimidine 10. 4,6-Dichloro-5-nitropyrimidine $\mathbf{1 1}(50 \mathrm{~g}, 0.26 \mathrm{~mol})$ and phenol $(200 \mathrm{~g})$ were heated under reflux at $140^{\circ} \mathrm{C}$ while a stream of ammonia was passed into the mixture for $4 \mathrm{~h}$. The phenol was removed by steam distillation and the residual suspension cooled and filtered. The residue was washed with water and then ethanol and the crystals of 4,6-diamino-5-nitropyrimidine 10 dried at $110^{\circ} \mathrm{C}$. Yield was $35.2 \mathrm{~g}$ (88\% yield), m. pt. $>280^{\circ} \mathrm{C}$ (lit. [34] $250^{\circ} \mathrm{C}$ ). The material showed the expected IR and ${ }^{1} \mathrm{H}$ NMR spectra.

Attempted N-oxidation of $\mathbf{1 0}$ : The same system of $30 \%$ hydrogen peroxide in trifluoroacetic acid as indicated above was used. Mass spec. confirmed the production of the 1,3-dioxide 6, but HPLC showed that the conversion was incomplete, with relatively large quantities of the monoxide 13 present. Attempts to separate the two materials by Soxhlet extraction led to degradation of the product.

\subsection{Thermal Stability Measurements of 5-Nitro- 2,4,6-Triaminopyrimidine-1,3-Dioxide 5}

5-Nitro-2,4,6-triaminopyrimidine-1,3-dioxide 5 was examined together with the following compounds (for comparison): ANPZ 2, PZO 3 and TATB. The temperature was changed in steps during the measurement from $80 \rightarrow 70 \rightarrow$ $60 \rightarrow 50{ }^{\circ} \mathrm{C}$. Measurements were also made at $40^{\circ} \mathrm{C}$. At the lower temperature the sample and the inert reference sample (acid-washed sand, Merck) were temporarily swapped to obtain a mirror image of the heatflow around the true baseline. This switch technique makes it possible to determine the true baseline accurately and to improve the measuring sensitivity.

The experiments were stopped when a steady state was reached which varied between 25 and 48 hours. The weight corrected heat flow measurements are shown in Table 1. 
Table 1. Constant heat flow measurements for NTAPDO 5, ANPZ 2, PZO 3 and TATB.

\begin{tabular}{lcccr}
\hline $\begin{array}{l}\mathrm{T} \\
\left({ }^{\circ} \mathrm{C}\right)\end{array}$ & $\begin{array}{l}\text { NTAPDO } \\
(\mu \mathrm{W} / \mathrm{g})\end{array}$ & $\begin{array}{l}\text { ANPZ } \\
(\mu \mathrm{W} / \mathrm{g})\end{array}$ & $\begin{array}{l}\mathrm{PZO} \\
(\mu \mathrm{W} / \mathrm{g})\end{array}$ & $\begin{array}{l}\text { TATB } \\
(\mu \mathrm{W} / \mathrm{g})\end{array}$ \\
\hline 80 & 10.02 & -3.43 & 0.23 & -3.98 \\
70 & 6.54 & -3.78 & 1.75 & -3.04 \\
60 & 1.80 & -1.27 & -0.87 & 0.67 \\
50 & 0.05 & -1.84 & -1.25 & 0.28 \\
40 & -0.10 & -1.99 & -1.2 & 0.65 \\
\hline
\end{tabular}

The heat flow measured from all four samples was very low. It was not possible to calculate the activation energies from the ANPZ, PZO and TATB results as the heat flows steps were not sufficiently large enough to obtain an accurate determination. In the case of the results for 5-nitro-2,4,6triaminopyrimidine-1,3-dioxide (5), calculations can be made at this level, although it is very important to get reliable values of the heat flow in each temperature range. Data collected from the sample of (5) indicated that there were possibly changes in the reaction mechanism at different temperature steps that could contribute to the heatflow drift.

\subsection{Synthesis of 2,3,6-Trichloro-5-Nitroquinoxaline 22}

2,3,6-Trichloroquinoxaline $\mathbf{2 1}$ (2.0 g, 9 mmol) was added gradually to $90 \%$ nitric acid $(10 \mathrm{ml})$ with stirring; the temperature rose to ca. $65^{\circ} \mathrm{C}$ then subsided. The mixture was stirred at ambient temperature for $90 \mathrm{~min}$., then poured onto crushed ice $(30 \mathrm{ml})$ with vigorous stirring. The resulting precipitate was allowed to stand overnight, then filtered off under suction and dried under vacuum overnight. The yield of 2,3,6-trichloro-5-nitroquinoxaline 22 was $1.8 \mathrm{~g}$ (64\%), m. pt. $170{ }^{\circ} \mathrm{C}$. The same product was obtainable using nitronium tetrafloroborate in sulfolane but in lower yield (ca. 20\%).

${ }^{1} \mathrm{H}$ NMR (acetone- $\mathrm{d}_{6}$ ), $\delta: 8.20$ (d, $\left.1 \mathrm{H}, \mathrm{J}=9.15 \mathrm{~Hz}\right) ; 8.35$ (d, $1 \mathrm{H}, \mathrm{J}=9.15 \mathrm{~Hz})$.

${ }^{13} \mathrm{C}$ NMR (acetone-d $\mathrm{d}_{6}$ ), $\delta: 126.59$ (C7); 131.83 (C8); 132.50 (C8a); 132.50 (C4a); 138.94 (C6); 144.27 (C5); 148.02 (C3); 148.94 (C2).

$v_{\max }\left(\mathrm{cm}^{-1}\right): 3073(\mathrm{w}), 1612(\mathrm{w}), 1562(\mathrm{~s}), 1366(\mathrm{~m}), 831(\mathrm{~m})$. Measured mass (by high res. MS): $277.9280(\mathrm{M}+1)^{+}$; calc. for $\left(\mathrm{C}_{8} \mathrm{H}_{3}{ }^{35} \mathrm{Cl}_{3} \mathrm{~N}_{3} \mathrm{O}_{2}\right)^{+}$: 277.9291 .

CHN combustion analysis: Found - C, 34.31; H, 0.70; $\mathrm{N}, 14.93 \%$. Calculated for $\mathrm{C}_{8} \mathrm{H}_{2} \mathrm{Cl}_{3} \mathrm{~N}_{3} \mathrm{O}_{2}-\mathrm{C}, 34.47 ; \mathrm{H}, 0.72$; $\mathrm{N}, 15.08 \%$.

\subsection{Synthesis of 2,3-Dihydroxy-6,7-Dinitroquinoxaline 25}

The method of Banihashemi \& Marvel [35] was adapted. 2,3-Dihydroxyquinoxaline 24 (4.86 g, $30 \mathrm{mmol})$ was added rapidly to a stirred mixture of conc. sulfuric acid $(32 \mathrm{ml})$ and potassium nitrate $(6.0 \mathrm{~g}, 60 \mathrm{mmol})$ at $0{ }^{\circ} \mathrm{C}$. The resulting mixture was stirred at this temperature for $15 \mathrm{~min}$, then at ambient temperature for $4 \mathrm{~h}$. After this time, the mixture was poured into ice-water $(200 \mathrm{ml})$, and the resulting precipitate filtered off under suction and dried in a stream of air overnight to give 2,3-dihydroxy-6,7-dinitroquinoxaline 25 as a yellow solid, $6.01 \mathrm{~g}(80 \%)$, m. pt. $>280{ }^{\circ} \mathrm{C}$ (lit. [35] m. pt. $>280^{\circ} \mathrm{C}$ ).

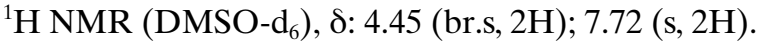
$v_{\text {max }}\left(\mathrm{cm}^{-1}\right): 3151$ (s, br.), $1719(\mathrm{~m}), 1560$ (s), 1335 (s).

\subsection{Synthesis of 2,3-Dimethoxy-6,7-Dinitroquinoxaline 26}

Sodium hydride (0.42 g, $18 \mathrm{mmol})$ was added slowly over $5 \mathrm{~min}$. under nitrogen to a stirred solution of 2,3-dihydroxy6,7-dinitroquinoxaline $\mathbf{2 5}(2.0 \mathrm{~g}, 8 \mathrm{mmol})$ in freshly distilled THF $(50 \mathrm{ml})$. The resulting mixture was then refluxed for $2 \mathrm{~h}$, after which time methyl iodide $(2.5 \mathrm{~g}, 18 \mathrm{mmol})$ was added and refluxing was continued for a further $2 \mathrm{~h}$. The reaction mixture was then cooled and poured onto crushed ice $(30 \mathrm{ml})$ giving a biphasic mixture. The organic layer was separated, the aqueous layer extracted with dichloromethane $(3 \times 35 \mathrm{ml})$, and the combined extracts were dried over anhyd. magnesium sulfate. After filtration, the solvent was removed under vacuum and 2,3-dimethoxy-6,7-dinitroquinoxaline 26 was obtained as red crystals, $1.49 \mathrm{~g}(67 \%)$, m. pt. $>280^{\circ} \mathrm{C}$ (dec.).

${ }^{1} \mathrm{H}$ NMR (DMSO-d $)$ ), $\delta: 3.44$ (s, 6H); 8.12 (s, 2H).

$v_{\text {max }}\left(\mathrm{cm}^{-1}\right): 1527(\mathrm{~m}), 1360(\mathrm{~m})$.

\subsection{Attempted Amination of 2,3-Dimethoxy- 6,7-Dinitroquinoxaline 26}

Use of ammonia in either methanol or acetonitrile solution at ambient temperature for $18 \mathrm{hr}$ to aminate 2,3-dimethoxy-6,7-dinitroquinoxaline gave unchanged starting material. Heating the methanolic mixture in an autoclave at temperatures up to $150^{\circ} \mathrm{C}$ gave the same result. These conditions had been successfully employed in the amination of 2,3-dichloroquinoxaline [9].

\subsection{Synthesis of 2,4,7-Triamino-6,8-Dinitroquinazoline 30}

Under nitrogen atmosphere, 2,4-diamino-6,8-dinitroquinazoline 29 ( $1.0 \mathrm{~g}, 4 \mathrm{mmol})$ was added with stirring to a mixture of 1,1-dimethylhydrazine $(3.6 \mathrm{~g}, 60 \mathrm{mmol})$ and methyl iodide $(8.52 \mathrm{~g}, 60 \mathrm{mmol})$ in freshly distilled DMSO $(50 \mathrm{ml})$. A freshly prepared solution of sodium methoxide [prepared from sodium $(2.6 \mathrm{~g})$ and dry methanol $(30 \mathrm{ml})$ ] was then added to the brown solution, which turned bright red. The mixture was stirred for 5 days at ambient temperature under nitrogen, then quenched by addition of $35 \%$ aq. $\mathrm{HCl}$ until white fumes were no longer produced (ca. $50 \mathrm{ml}$ of $\mathrm{HCl}$ soln. required). After addition to crushed ice, the product mixture was extracted with ethyl acetate $(3 \times$ $300 \mathrm{ml}$ ), and the combined extracts were dried over anhyd. magnesium sulfate and concentrated under vacuum. The 
resulting brown liquid was purified by column chromatography (stationary phase: silica gel 40 (Merck); mobile phase: gradient from ethyl acetate/hexane 2:1 (vol./vol.) to pure ethyl acetate). Evaporation of the eluant gave a brown solid, m. pt. $>280^{\circ} \mathrm{C}$ identified as 2,4,7-triamino-6,8-dinitroquinazoline 30 by its NMR and mass spectra.

${ }^{1} \mathrm{H}$ NMR (DMSO-d $)$ ), ঠ: 3.27 (br.s, 3H); 9.22 (s, 5H).

${ }^{13}$ C NMR (DMSO-d 6 ), $\delta: 129.50$ (C4a); 131.73 (C5); 144.10 (C6); 148.62 (C8); 150.65 (C7); 153.13 (C8a); 155.07 (C4); $161.70(\mathrm{C} 2)$.

$v_{\max }\left(\mathrm{cm}^{-1}\right): 3462(\mathrm{~s}), 1626(\mathrm{~m}), 1275(\mathrm{~m})$.

Measured mass (by high res. MS): $266.0646(\mathrm{M}+1)^{+}$; calc. for $\left(\mathrm{C}_{8} \mathrm{H}_{8} \mathrm{~N}_{7} \mathrm{O}_{4}\right)^{+}: 266.0638$.

\subsection{Synthesis of 2,4-Diamino-6,8-Dinitroquinazoline- $\mathbf{N}, \mathbf{N}^{\prime}$-Dioxide 31}

$60 \%$ wt./vol. hydrogen peroxide solution (0.70 g, $12 \mathrm{mmol})$ in trifluoroacetic acid $(35 \mathrm{ml})$ was added dropwise with stirring to a solution of 2,4-diamino-6,8-dinitroquinazoline 29 (1.0 g, $4 \mathrm{mmol})$ in trifluoroacetic acid $(35 \mathrm{ml})$ at $0{ }^{\circ} \mathrm{C}$. During addition the temperature rose to $5^{\circ} \mathrm{C}$; stirring was continued overnight at ambient temperature. The mixture was then added to crushed ice, the acid was neutralised by addition of sodium hydrogen carbonate, and the resulting aqueous solution was evaporated to dryness. The solid residue was extracted with acetone and the organic solution was concentrated at atmospheric pressure to give an orange-brown solid $(0.40 \mathrm{~g}, 36 \%)$, m.pt. $>280^{\circ} \mathrm{C}$, identified as 2,4-diamino-6,8-dinitroquinazoline-N, $\mathrm{N}^{\prime}$-dioxide $\mathbf{3 1}$ from its NMR and mass spectra.

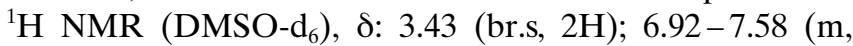
$12 \mathrm{H})$.

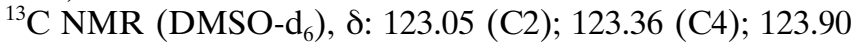
(C8a); 124.38 (C4a); 125.88 (C7); 126.52 (C5); 136.91 (C8); 144.80 (C6).

$v_{\max }\left(\mathrm{cm}^{-1}\right): 3430$ (br.s), 3328 (br.s), 1533 (m), 1348 (m), $1208(\mathrm{~m})$.

$m / z: 281(\mathrm{M}-1)^{+}$.

\subsection{2,4,6,8-Tetra-Aminoquinazoline 32}

A mixture of 2,4-diamino-6,8-dinitroquinazoline 29 $(1.0 \mathrm{~g}, 4 \mathrm{mmol})$ and $3 \% \mathrm{Pd} / \mathrm{C}$ catalyst in ethanol $(250 \mathrm{ml})$ was hydrogenated at $200 \mathrm{kPa}$ for $4 \mathrm{~h}$. Filtration of the resulting mixture followed by removal of solvent under vacuum gave 2,4,6,8-tetra-aminoquinazoline $\mathbf{3 2}$ as a light brown solid, $0.60 \mathrm{~g}(79 \%)$, m.pt. $>280^{\circ} \mathrm{C}$ (Ref. [29] $\left.240^{\circ} \mathrm{C}\right)$.

Caution: Care should be taken to keep the catalyst moist (with ethanol) at the filtration stage as the dry material is pyrophoric.

${ }^{1} \mathrm{H}$ NMR (DMSO-d ${ }_{6}$ ), $\delta: 3.41$ (br.s, 2H); 6.24 (d, 7H, $J=$ $3.0 \mathrm{~Hz}) ; 7.08(\mathrm{~d}, 5 \mathrm{H}, J=3.0 \mathrm{~Hz})$.

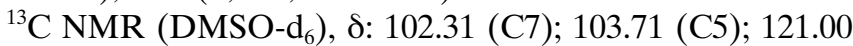
(C4a); 142.53 (C6); 144.52 (C8); 148.84 (C8a); 163.27 (C4); $163.46(\mathrm{C} 2)$. $v_{\max }\left(\mathrm{cm}^{-1}\right): 3323$ (br.s), 3185 (br.s).

Measured mass (by high res. MS): 190.0958 (M) ${ }^{+}$; calc. for $\left(\mathrm{C}_{8} \mathrm{H}_{10} \mathrm{~N}_{6}\right)^{+}: 190.0967$.

\subsection{Attempted Nitration of 2,4,6,8-Tetra- Aminoquinazoline 32}

$100 \%$ nitric acid $(2.0 \mathrm{ml})$ was added dropwise to stirred acetic anhydride $(35 \mathrm{ml})$ keeping the temperature in the range 0 to $5^{\circ} \mathrm{C}$. 2,4,6,8-Tetra-aminoquinazoline $\mathbf{3 2}(0.25 \mathrm{~g}$, $1.3 \mathrm{mmol}$ ) was added, the mixture was allowed to warm to ambient temperature, and stirring was continued overnight. The mixture was added to crushed ice $(50 \mathrm{ml})$ and extracted with ethyl acetate, but no reaction product could be isolated (i.e. all products water soluble).

\subsection{Synthesis of Pteridine Derivative 38 via 2-Amino- 3-Cyano-6-(Oximino-Methyl)-Pyrazine-1-Oxide 37}

2-Amino-3-cyano-6-(oximinomethyl)pyrazine-1-oxide 37 was prepared from dioximinoacetone 39 and 2-(tosylamino)malononitrile $\mathbf{4 0}$ by the method of Touster [31]. Treatment of $\mathbf{3 7}$ with guanidinium chloride according to Taylor's method [30] gave the pteridine derivative 38 in $85 \%$ yield. 38 was a high melting compound, insoluble in all common solvents, which defeated attempts at further reaction or characterisation owing to its insolubility (e.g. attempted acetylation using either acetic anhydride or acetyl chloride gave no reaction). Because of its insolubility no further work was carried out on $\mathbf{3 8}$.

\subsection{Synthesis of 2,6,8-Trichloropurine 42}

Phosphorus oxychloride $(200 \mathrm{ml})$ was added to uric acid $(40 \mathrm{~g}, 0.23 \mathrm{~mol})$ and freshly distilled N,N-dimethylaniline $(91.0 \mathrm{ml})$ under nitrogen and the mixture was heated to reflux for $20 \mathrm{~h}$. The reaction mixture was cooled to room temperature and then crash precipitated by pouring carefully into iced water $(1500 \mathrm{ml})$ with vigorous stirring. A brown precipitate formed. The aqueous layer was removed by filtration and the solid residue was washed with diethyl ether $(3 \times 250 \mathrm{ml})$ and the aqueous filtrate was extracted using the diethyl ether $(3 \times 250 \mathrm{ml})$ from the residue wash. The ether extracts were combined and the solvent removed under vacuum to afford crude $\mathbf{4 2}$ a yellow solid. This was dissolved in boiling aqueous ammonia (120 ml, $3 \mathrm{M})$ and then cooled to room temperature; a white precipitate formed. The precipitate $(8.2 \mathrm{~g})$ was filtered off and added to water (10 $\mathrm{ml})$ and then heated to reflux, dilute sulphuric acid was added dropwise to acidify the solution then Norit B was added. The mixture was refluxed for $20 \mathrm{~min}$. The solution was filtered hot, and a white precipitate formed on cooling which was filtered off. The solid was dried at $100^{\circ} \mathrm{C}$ for $72 \mathrm{~h}$ to afford anhydrous 2,6,8-trichloropurine 42 (2.8 g, 5.4\% yield) as a white powder. 
${ }^{13}$ C NMR (DMSO-d ${ }_{6}$ ), $\delta: 156.6,150.9,146.4,145.8,129.3$. $v_{\max }\left(\mathrm{cm}^{-1}\right): 3045$ (NH str.), 2960 (NH str.).

Chemical ionisation $\mathrm{MS}-\mathrm{NH}_{3}$ ionising gas $-\mathrm{M}^{+}: 239$ $\left(\mathrm{M}^{+} . \mathrm{NH}_{3}\right), 233\left(\mathrm{M}^{+}\right), 204\left(\mathrm{M}^{+} \cdot \mathrm{N}_{\mathrm{H} 3}-\mathrm{Cl}\right), 189\left(\mathrm{M}^{+}-\mathrm{Cl}\right), 170$ $\left(\mathrm{M}^{+} . \mathrm{N}_{\mathrm{H} 3}-2 \mathrm{Cl}\right), 155\left(\mathrm{M}^{+}-2 \mathrm{Cl}\right)$.

\subsection{Synthesis of 6-Amino-2,8-Dichloropurine 46}

2,6,8-Trichloropurine $(0.327 \mathrm{~g}, 1.46 \mathrm{mmol})$ and acetonitrile $(50 \mathrm{ml})$ were added to an autoclave. The autoclave was flushed with ammonia for 4 min then charged with ammonia. The autoclave was sealed and the reaction heated to $135^{\circ} \mathrm{C}$ with stirring, which resulted in a pressure of $1.2 \mathrm{MPa}$. Heating was continued for $6 \mathrm{~h}$ and the reaction then allowed to cool to room temperature. The residual pressure was released carefully and a small sample of the reaction mixture was submitted for HPLC analysis [mobile phase: acetonitrile:water (60:40); stationary phase: RP-18 (Merck)].

Two compounds were present:

- 2,6,8-trichloropurine $\mathbf{4 2} \approx 54.8 \%$

- 6-amino-2,8-dichloropurine $46 \approx 45.2 \%$

MS (EI) of 46: $m / z 203\left(\mathbf{M}^{+}\right), 168\left(\mathbf{M}^{+}-\mathrm{Cl}\right)$.

When the reaction time was extended to $20 \mathrm{~h}$ under the same conditions, 2,6,8-trichloropurine $\mathbf{4 2}$ was still present but there were 11 other components in the HPLC (one of which was 6-amino-2,8-dichloropurine 46); thus it was apparent that breakdown of the heterocyclic ring was occurring under these conditions and that a well optimised synthesis of 6-amino-2,8-dichloropurine $\mathbf{4 6}$ was not possible by this method.

Earlier attempts to aminate 2,6,8-trichloropurine $\mathbf{4 2}$ by treatment with ammonia gas (at 1 atmosphere) in either a) acetonitrile or b) phenol (conditions as described for pyrimidine 10) yielded the following: a) the ammonium salt of 2,6,8-trichloropurine $\mathbf{4 2}$, a labile yellow solid, or b) a complex mixture of products containing unchanged $\mathbf{4 2}$, some 6-amino-2,8-dichloropurine $\mathbf{4 6}$ and (from MS) various phenoxy-containing by-products.

\section{References}

[1] Presented in part at 33nd Int. Annual Conference of ICT, Karlsruhe, Germany, June 25-28, 2002, pp. IV/1.

[2] A. Sanderson (Ed.), What Makes a Useable New Energetic Material, Proc. 1994 NIMIC Workshop, NATO Headquarters, Brussels, Belgium, June 22 -24, 1994.

[3] T. Urbanski, S. K. Vasudeva, Heat Resistant Explosives, J. Sci. Ind. Res. 1978, 37, 250.

[4] T. Urbanski, Chemistry and Technology of Explosives, Pergamon Press, Oxford, 1984, Vol. 4, Ch. 7.

[5] M. Coburn et al, 3-Nitro-1,2,4-triazol-5-one, A Less Sensitive Explosive, J. Energ. Mater. 1987, 5, 27.

[6] A. Becuwe, A. Delclos, Low-Sensitivity Explosive Compounds for Low Vulnerability Warheads, Propellants, Explos., Pyrotech. 1993, 18, 1 .

[7] P. F. Pagoria, A. R. Mitchell and R. D. Schmidt, Synthesis, Scale-up and Experimental Testing of LLM-105, Proc.
NDIA(ADPA) Conference on Insensitive Munitions \& Energetic Materials Technology, San Diego, CA, 1998.

[8] J. Kerth, W. Kuglstatter, Synthesis and Characterization of 2,6Diamino-3,5-Dinitropyrazine-1-Oxide (NPEX-1), 32nd Int. Annual Conference of ICT, Karlsruhe, Germany, July 3-6, 2001, pp. $166 / 1$.

[9] S. P. Philbin, R. W. Millar and R. G. Coombes, Studies of Novel Nitro-Substituted Nitrogen Heterocycles, NDIA(ADPA) Conference on Insensitive Munitions \& Energetic Materials Technology, Tampa FL, Nov./Dec. 1999.

[10] S. P. Philbin, R. W. Millar and R. G. Coombes, Preparation of 2,5-Diamino-3,6-Dinitropyrazine (ANPZ-i): A Novel Candidate High Energy Insensitive Explosive, Propellants, Explos., Pyrotech. 2000, 25, 302.

[11] T. J. Delia, D. E. Portlock and D. L. Venton, Pyrimidine Noxides. Oxidation of 5-Nitroso-2,4,6-Triaminopyrimidine, $J$. Heterocycl. Chem., 1968, 5, 449.

[12] R. A. Hollins, L. H. Merwen, R. A. Nissan, W. S. Wilson and R. D. Gilardi, Mater. Res. Soc. Symp. Proc. (Decomposition, Combustion and Detonation Chemistry of Energetic Materials), 1996, 418,31 .

[13] M. D. Cook, QinetiQ Fort Halstead, personal communication, 1995.

[14] Royal Ordnance Provisional Hazard Data Sheet No. 82A, March 1989.

[15] MOD SCC Manual, General Appendix E, March 1981.

[16] R. W. Millar, R. P. Claridge., J. Hamid, D. Shaw and S. P. Philbin, unpublished MOD report 1998.

[17] A. Albert, D. J. Brown and G. Cheeseman, Pteridine Studies. I. Pteridine and 2- and 4-Amino-and 2- and 4-Hydroxypteridines, J. Chem. Soc. 1951, 474.

[18] A. R. Katritzky, J. N. Lam, Heterocyclic N-Oxides and NImides, Heterocycles, 1992, 33, 1011.

[19] H.-H. Licht, H. Ritter, Neue Explosivstoffe: Dinitropyridine, 24th Int. Annual Conference of ICT, Karlsruhe, Germany, June 29 - July 2, 1993, pp. 6/1.

[20] R. A. Hollins, L. H. Merwen, R. A. Nissan and W. S. Wilson, Aminonitropyridines and their N-Oxides, J. Heterocycl. Chem., 1996, 33, 895.

[21] R. P. Claridge et al., unpublished MOD report, 2001.

[22] W. M. Koppes, G. W. Lawrence, M. E. Sitzmann and H. G. Adolph, Reaction of 1,3,5-Trifluorotrinitrobenzene with $\mathrm{Nu}-$ cleophiles, J. Chem. Soc. Perkin Trans. 1 1981, 1815.

[23] R. D. Chambers, C. Hall, J. Hutchinson and R. W. Millar, Polyhalogenated Heterocyclic Compounds, Part 42: Fluorinated Nitrogen Heterocycles with Unusual Substitution Patterns, J. Chem. Soc. Perkin Trans. 1 1998, 1705.

[24] R. W. Millar, S. P. Philbin, R. P. Claridge and J. Hamid, Novel Heterocyclic Insensitive High Explosive Compounds: Pyridines, Pyrimidines, Pyrazoles and Related Compounds, NDIA(ADPA) Conference on Insensitive Munitions \& Energetic Materials Technology, Bordeaux, France, 8-12 October 2001.

[25] G. W. H. Cheeseman, Quinoxalines and Related Compounds. VI. Substitution of 2,3-Dihydroxyquinoxaline and its 1,4Dimethyl Derivative, J. Chem. Soc. C, 1962, 1170.

[26] R. Nasielski-Hinkens, J. Kotel, T. Lecloux and J. Nasielski, 5Amino-6-nitroquinoxalines from 6-nitroquinoxalines by the Amination Reaction with Hydroxylamine, Synth. Commun. 1989, 19, 511.

[27] K. Wagner and E. Roos, UK Patent 1,228,536, 1971.

[28] P. F. Pagoria, A. R. Mitchell and R. D. Schmidt, 1,1,1-Trimethylhydrazinium Iodide: A Novel, Highly Reactive Reagent for Aromatic Amination via Vicarious Nucleophilic Substitution of Hydrogen, J. Org. Chem., 1996, 61, 2934.

[29] E. F. Elslager, J. Clarke, L. M. Werbel, D. F. Worth and J. Davoll, Antimalarial Drugs. 25. Folate Antagonists. 3. 2,4Diamino-6- (heterocyclic)quinazolines, a Novel Class of Antimetabolites with Potent Antimalarial and Antibacterial Activity, J. Med. Chem., 1972, 15, 827. 
[30] E. C. Taylor, K. L. Perlman, Y.-H. Kim, I. P. Sword and P. A. Jacobi, . Pteridines. XXIX. Unequivocal Route to 2,4-Diamino-6-substituted Pteridines, J. Am. Chem. Soc., 1973, 95, 6413.

[31] O. Touster, Nitrosation of Aliphatic Carbon Atoms, Organic Reactions 1953, 7, 327.

[32] P. J. Honey, R. W. Millar and R. G. Coombes, Re-Investigation of the Ponzio Reaction for the Preparation of Gem-Dinitro Compounds, ACS Symp. Ser. 623, Ch. 13, American Chemical Society, Washington DC, 1996.

[33] R. W. Millar, R. P. Claridge, Reversed Dipole ('Umpolung') Nitrations: Novel Syntheses of Polynitroaromatic Compounds, 29th Internat. Annual Conf. ICT, Karlsruhe, Germany, June 30 - July 3, 1998; see also R. W. Millar, R. P. Claridge, J. P. B. Sandall and C. Thompson, Novel Syntheses of Polynitroaromatic Compounds by Reversed-Dipole ('Umpolung') Nitrations, Arkivoc (on-line journal), 2001, www.Arkat-usa. org.

[34] D. Binder, C. R. Noe, B. C. Prager and F. Turnowsky, Pyrazine1,4-Dioxides Fused to Heterocycles. 3. Synthesis and Antibacterial Activity of Substituted Pteridine-5,8-Dioxides, Arzneimittel-Forschung, 1983, 33, 803 (Chem Abs. 99:105047).

[35] A. Banihashemi, C. S. Marvel, Polymers with Recurring Quinoxaline Units. V. Poly(6H-imidazo[4,5-g]oxazolo[4,5b]quinoxaline-2,7-diyl-m-phenylene), J. Polym, Sci. Part A-1, 1969, 7, 2746 .

\section{Abbreviations}

$A N P Z$

$A N P Z-i$

2,6-Diamino-3,5-dinitropyrazine (precursor to PZO) 2,5-Diamino-3,6-dinitropyrazine (precursor to PZDO)

$B A M O$

\section{$C L-20$ \\ Hexanitrohexaazaisowurtzitane}

$D A D N P O \quad$ 2,6-Diamino-3,5-dinitropyridine-1-oxide

$D M D \quad$ Dimethyldioxirane

GlyN Glycidyl nitrate

$H E \quad$ High explosive

$H F C \quad$ Heat flow calorimetry

$H M X \quad$ 1,3,5,7-Tetranitro-octahydro-1,3,5,7-tetrazocine

HNS Hexanitrostilbene

IHE Insensitive high explosive

LLNL Lawrence Livermore National Laboratory, Calif., USA

NIMMO 3-Methyl-3-(nitratomethyl)oxetane

NTAPDO 5-Nitro-2,4,6-triaminopyrimidine-1,3-dioxide

NTO 5-Nitro-1,2,4-triazolin-2-one

$P_{C-I} \quad$ Detonation pressure (Chapman-Jouguet point)

$P Y X \quad$ 2,5-Bis(picrylamino)-3,5-dinitropyridine

$P Z D O \quad$ 2,5-Diamino-3,6-dinitropyrazine-1,4-dioxide

$P Z O \quad$ 2,5-Diamino-3,5-dinitropyrazine-1-oxide

$R D X \quad$ 1,3,5-Trinitrohexahydro-1,3,5-triazine

TATB 1,3,5-Triamino-2,4,6-trinitrobenzene

TNAZ 1,3,3-Trinitroazetidine

TNT 2,4,6-Trinitrotoluene

\section{Acknowledgements}

This work forms part of the UK MoD Corporate Research Programme, from which funding is gratefully acknowledged. The authors would like to thank the following QinetiQ colleagues for their contributions: Dr Eamon Colclough, Dr Anthony Cunliffe, Dr Simon Torry, Mr James Dodds and Mr David Shaw. Input from collaborations with the Universities of Durham, Exeter and Brunel is also gratefully acknowledged.

(Received August 22, 2003; Ms 2003/040) 